
FERROVIÁRIO E RODOVIÁRIO NO TRANSPORTE DE RESÍDUOS SÓLIDOS URBANOS

\title{
USE OF SYSTEMS DYNAMICS FOR COMPARATIVE BETWEEN RAIL AND ROAD MODELS FOR THE TRANSPORT OF SOLID URBAN WASTE
}

\section{USO DE LA DINÁMICA DE SISTEMAS PARA COMPARATIVO ENTRE LOS MODALES FERROVIARIO Y DE CARRETERAS EN EL TRANSPORTE DE RESIDUOS SÓLIDOS URBANOS}

Flaviani Souto Bolzan Medeiro

Doutora em Administração pela Universidade Federal de Santa Maria (UFSM)

flaviani.13@gmail.com

https://orcid.org/0000-0002-7693-6919

Glauco Oliveira Rodrigues

Doutorando no Programa de Pós-Graduação em Administração na Universidade Federal de Santa Maria (PPGA/UFSM

glaucop10@ redes.ufsm.br

Eugênio de Oliveira Simonetto

Doutor em Administração pela Universidade Federal do Rio Grande do Sul (UFRGS); Professor Adjunto no Departamento de Ciências Administrativas da Universidade Federal de Santa Maria (UFSM) eosimonetto@gmail.com

https://orcid.org/0000-0001-7572-5338

Wellington Furtado Santos

Doutor em Administração pela Universidade Federal de Santa Maria (UFSM); Professor Titular no Instituto Federal Farroupilha (Campus São Vicente do Sul)

wellington.furtado@gmail.com

https://orcid.org/0000-0001-9612-4339

Editor Científico: José Edson Lara

Organização Comitê Científico

Double Blind Review pelo SEER/OJS

Recebido em 10.05.2019

Aprovado em 30.07.2020

Este trabalho foi licenciado com uma Licença Creative Commons - Atribuição - Não Comercial 3.0 Brasil 


\title{
Resumo
}

Objetivo: o presente artigo tem como objetivo realizar um comparativo financeiro e ambiental entre os modais ferroviário e rodoviário no transporte de Resíduos Sólidos Urbanos (RSU) via simulação baseada na Dinâmica de Sistemas.

Metodologia / abordagem: este trabalho, que teve como base a Dinâmica de Sistemas, adotou para a modelagem a metodologia proposta por Law (2015). Destarte, logo após a definição de todas as equações e suas relações, o modelo foi simulado considerando um horizonte de tempo de onze anos.

Originalidade / Relevância: a temática dos RSU se tornou um problema na gestão das cidades. O crescimento populacional, o aumento do poder de compra e o rápido avanço da tecnologia contribuem para os impactos negativos tanto financeiros como ambientais causados pelos RSU. Logo, esta pesquisa é relevante ao passo que contempla novas discussões na busca de possíveis alternativas no intuito de amenizar os problemas enfrentados pelos gestores.

Principais resultados: os resultados obtidos revelam que, visto de uma perspectiva financeira, há uma grande diferença existente entre os modais rodoviário e ferroviário no transporte dos RSU. O estudo demonstra a importância da valorização das ferrovias, e também, apresenta-se como outra opção aos gestores para o transporte dos RSU nas suas cidades. É pertinente frisar que o modal ferroviário não substitui o modal rodoviário, mas sim, poderia vir a ser melhor explorado em razão dos benefícios oriundos da sua adoção.

Contribuições teóricas / metodológicas: ao utilizar a Dinâmica de Sistemas, este trabalho contribuiu com um modelo que poderá vir a auxiliar os gestores na logística dos RSU, ao realizar um comparativo do transporte desses resíduos por trem e por caminhão. Ao elaborar modelos computacionais, isso possibilita uma análise mais detalhada do comportamento das variáveis ao longo do tempo. Deste modo, permitirá além de uma melhor compreensão do problema investigado também possibilitará que as decisões possam ser tomadas visando atender às futuras necessidades e demandas.

Palavras-chave: Resíduos Sólidos Urbanos; Modais de Transporte; Dinâmica de Sistemas.

\begin{abstract}
Objective: this article aims to make a financial and environmental comparison between the rail and road modes in the transport of Solid Urban Waste (SUW) via simulation based on Systems Dynamics.
\end{abstract}

Methodology / approach: this work, which was based on Systems Dynamics, adopted the methodology proposed by Law (2015) for modeling. Thus, after defining all equations and their relationships, the model was simulated considering an eleven-year time horizon.

Originality / relevance: the theme of SUW has become a problem in city management. Population growth, increased purchasing power and the rapid advance of technology contribute to the negative financial and environmental impacts caused by SUW. Therefore, this research 
is relevant as it contemplates new discussions in the search for possible alternatives in order to alleviate the problems faced by managers.

Main results: the results obtained reveal that, seen from a financial perspective, there is a great difference between road and rail modes in the transport of SUW. The study demonstrates the importance of upgrading the railways, and also presents itself as another option for managers to transport SUW in their cities. It is pertinent to emphasize that the railway modal does not replace the road modal, but rather, it could be better exploited due to the benefits arising from its adoption.

Theoretical / methodological contributions: using System Dynamics, this work contributed with a model that could help managers in the SUW logistics, when comparing the transport of these residues by train and truck. When elaborating computational models, this allows a more detailed analysis of the behavior of variables over time. In this way, it will allow, in addition to a better understanding of the problem investigated, it will also allow decisions to be made in order to meet future needs and demands.

Keywords: Solid urban waste; Modes of transport; Systems dynamics.

\section{Resumen}

Objetivo: este artículo tiene como objetivo hacer una comparación financiera y ambiental entre los modos ferroviario y vial en el transporte de Residuos Sólidos Urbanos (RSU) a través de la simulación basada en la Dinámica de Sistemas

Metodología / enfoque: este trabajo, que se basó en la dinámica de sistemas, adoptó la metodología propuesta por Law (2015) para el modelado. Por lo tanto, después de definir todas las ecuaciones y sus relaciones, el modelo se simuló considerando un horizonte temporal de once años.

Originalidad / relevancia: el tema de los RSU se ha convertido en un problema en la gestión de la ciudad. El crecimiento de la población, el aumento del poder adquisitivo y el rápido avance de la tecnología contribuyen a los impactos negativos financieros y ambientales causados por los RSU. Por lo tanto, esta investigación es relevante ya que contempla nuevas discusiones en la búsqueda de posibles alternativas para aliviar los problemas que enfrentan los gerentes.

Resultados principales: los resultados obtenidos revelan que, visto desde una perspectiva financiera, existe una gran diferencia entre los modos de carretera y ferrocarril en el transporte de RSU. El estudio demuestra la importancia de mejorar los ferrocarriles, y también se presenta como otra opción para que los gerentes transporten RSU en sus ciudades. Es pertinente enfatizar que el modal ferroviario no reemplaza al modal vial, sino que podría explorarse mejor debido a los beneficios derivados de su adopción.

Contribuciones teóricas / metodológicas: utilizando Systems Dynamics, este trabajo contribuyó con un modelo que puede ayudar a los gerentes en la logística de RSU, al comparar el transporte de estos residuos en tren y camión. Al elaborar modelos computacionales, esto permite un análisis más detallado del comportamiento de las variables a lo largo del tiempo. De 
esta manera, permitirá, además de una mejor comprensión del problema investigado, también permitirá tomar decisiones para satisfacer las necesidades y demandas futuras.

Palabras clave: Resíduos Sólidos Urbanos; Modos de transporte; Dinámica de Sistemas.

\section{Introdução}

Os Resíduos Sólidos Urbanos (RSU) apresentam-se como um grande problema da sociedade - com mais intensidade nas áreas urbanas - agravando os problemas ambientais já existentes e acarretando no surgimento de outros onde, na maioria das vezes, relacionados às formas inadequadas de disposição e ineficiência na gestão dos mesmos (Trombeta \& Leal, 2014). Gouveia (2012) ressalta que, embora o Brasil seja um território que apresenta grandes diferenças regionais, a produção de resíduos tem aumentado em todas as regiões e Estados do país e boa parte destes resíduos não tem uma destinação sanitária e ambiental apropriada.

Comumente, os RSU são depositados em vazadouros a céu aberto - nos lixões - uma forma menos prejudicial seria nos aterros controlados, uma vez que os resíduos são recobertos por terra, ou, nos aterros sanitários que, pelo modo de tratamento adotado, reduz os impactos ambientais e os danos à saúde humana oriundos do seu descarte (Frota, Tassigny, Bizarria, \& Oliveira, 2015). Deus, Battistelle e Silva (2015) julgam que no Brasil o investimento na gestão de resíduos sólidos é algo fundamental tanto para seu desenvolvimento quanto para seu crescimento.

Ademais, Padula (2008) entende que, considerando as dimensões do país, uma infraestrutura de transportes é essencial para o seu desenvolvimento. Contudo, por um lado, na maior parte das empresas, segundo Ballou (2006) e Castiglioni e Pigozzo (2014), o transporte é o elemento mais importante quando se trata de custo logístico. Por outro lado, Nunes e Silva (2015) explicam que coletar os resíduos sólidos quer dizer recolher o lixo acondicionado por quem o produziu para então encaminhá-lo, através do transporte adequado, a uma possível estação de transferência para o devido tratamento e a sua destinação final. Destarte, na visão de Colavite e Konish (2015), compreender e conhecer as relações entre as diferentes características dos modais de transporte passa a ser um imperativo no que se refere à gestão do transporte de cargas.

Diante do exposto, o presente artigo tem como objetivo realizar um comparativo financeiro e ambiental entre os modais ferroviário e rodoviário no transporte de resíduos sólidos urbanos via simulação baseada na Dinâmica de Sistemas. A motivação para este estudo se deve 
a fatores como: (a) no Brasil - um país que possui renda per capita tida como intermediária é produzido diariamente 1,23 kg/hab./dia (Rodrigues, Magalhães Filho, \& Pereira, 2016); além disso, (b) o transporte de cargas no país é altamente dependente das rodovias (Bartholomeu \& Caixeta Filho, 2008); (c) onde tal dependência vem a ser um problema quando se consideram as dimensões continentais do país e sua infraestrutura rodoviária tanto precária como insuficiente (Pontes, Carmo, \& Porto, 2009); (d) logo, se faz necessário investigar meios que viabilizem estruturas de tal forma que gerem um menor impacto (Morais \& Colesanti, 2014).

Quanto à estrutura, após esta seção introdutória apresenta-se o referencial teórico. Em seguida, consta a metodologia adotada. Na sequência, segue a descrição do desenvolvimento do modelo e experimento e, posteriormente, encerra-se com as considerações finais acompanhada de recomendações para pesquisas futuras.

\section{Referencial teórico}

\subsection{O modal ferroviário no Brasil}

Segundo a Agência Nacional de Transportes Terrestres [ANTT] (2017), a rede ferroviária do Brasil possui ao todo 29.706 quilômetros, concentrando-se nas regiões Sul, Sudeste e Nordeste do país e atendendo também parte das regiões Centro-Oeste e Norte. Na Figura 1 visualiza-se o mapa ferroviário nacional. 


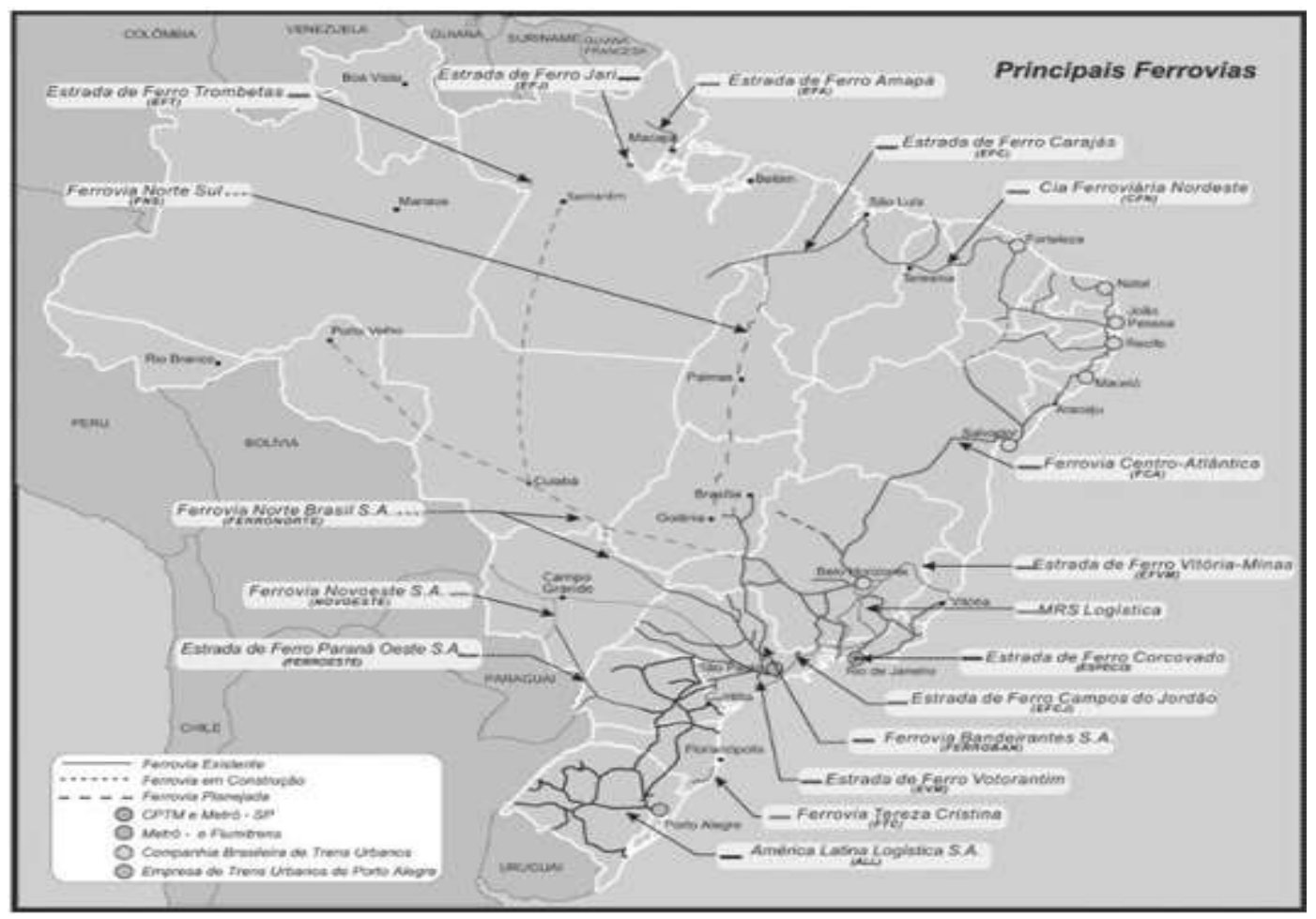

Figura 1. Mapa do sistema ferroviário nacional Fonte: ANTT (2017).

O sistema ferroviário no Brasil chegou a ter 34.207 quilômetros, entretanto, pela falta de investimentos em infraestrutura e na modernização das vias pelo poder público, acompanhado pelo crescimento do modal rodoviário, consequentemente, isso acarretou na erradicação de parte da sua rede ferroviária (Marinho, Souza, Silva, Meirelles, \& Pinto Junior, 2013). De acordo com Silveira (2003), o período auge do setor no país teve início em 1854 - ano da construção da primeira ferrovia com 14,5 quilômetros - e perdurou até 1930 (início da implementação da política rodoviarista no Brasil), ano este em que atingiu 32.478 quilômetros de linhas construídas, mas, a partir da década de 1970 entrou em decadência e isso vai até metade da década de 1990, ocasião em que foi concedida à iniciativa privada.

Conforme a Confederação Nacional de Transporte [CNT] (2013), para realizar essas concessões a estrutura escolhida pelo governo federal foi a separação vertical, isto é, a organização responsável pela concessão controla a infraestrutura, bem como a operação, e ainda, a comercialização dos serviços de transporte ferroviário numa certa região, cujo prazo de concessão é de 30 anos sendo prorrogáveis por igual período (as licitações ocorreram entre os anos de 1996 e 1998). Santos (2011, p. 146) lembra que a privatização da Rede Ferroviária Federal S.A. [RFFSA] - concessionária do serviço público de transporte ferroviário - foi 
incluída no Plano Nacional de Desestatização através do Decreto n. 473, de março de 1992, porém, tal privatização não resultou na melhoria das principais ineficiências do sistema: "as viagens são curtas, as velocidades são baixas e a integração modal é pequena".

Todavia, Wanke (2010) pondera que de todos os problemas que prejudicam o transporte de cargas no país - como no caso das ferrovias a má conservação das vias - o que certamente mais preocupa é a distorção da matriz de transportes, isso porque em países com grandes extensões territoriais como os Estados Unidos, Canadá, China e Rússia usam de forma predominante o sistema ferroviário e aquaviário em detrimento do modal rodoviário e no Brasil acontece o contrário, ou seja, há um predomínio deste modal. Na Figura 2 consta a participação de cada modal na matriz do transporte de cargas no país.

\begin{tabular}{|l|c|c|}
\hline \multicolumn{1}{|c|}{ Modal } & Milhões (TKU*) & Participação (\%) \\
\hline Rodoviário & 485.625 & 61,1 \\
\hline Ferroviário & 164.809 & 20,7 \\
\hline Aquaviário & 108.000 & 13,6 \\
\hline Dutoviário & 33.300 & 4,2 \\
\hline Aéreo & 3.169 & 0,4 \\
\hline Total & 794.903 & 100,0 \\
\hline
\end{tabular}

Figura 2: Matriz do transporte de cargas brasileiro

*Nota: Tonelada quilômetro útil

Fonte: CNT (2018).

Uma das metas para o ano de 2025 do Plano Nacional de Logística e Transportes [PNLT] (2009) é alcançar um equilíbrio entre os três modais com as seguintes participações: (a) rodoviário - 33\%; (b) ferroviário - 32\%; e (c) aquaviário - 29\%. Zioni e Freitas (2015) comentam que o PNLT contempla objetivos, metas e planos visando a ampliação da infraestrutura do país no futuro. Deste modo, o PNLT marca uma retomada do processo de planejamento no setor de transporte, superando assim, um gargalo de mais de 20 anos sem estudos voltados para o setor logístico no Brasil (Vieira, 2015).

\subsection{Análise comparativa entre os modais ferroviário e rodoviário}

O modal ferroviário diz respeito ao tipo de transporte que circula sobre trilhos entre cidades e os metrôs que circulam dentro de cidades (Marques \& Oda, 2012). Já o rodoviário, Souza e Markoski (2012) explicam que este faz uso de estradas de rodagem por meio de veículos como caminhões e carretas para o transporte. No Brasil, o modal rodoviário é o mais utilizado atingindo quase todos os pontos do território brasileiro (Gomes, 2004; Magalhães, Santos, Elia, \& Pinto, 2013; Faria \& Costa, 2015). 
Os autores Seleme, Tejada, Paula, Castanheira, \& Cardoso (2012) e Santos e Silva (2015) consideram que tal representatividade se deve ao fato das características dos investimentos realizados ao longo das últimas décadas que privilegiou esta modalidade. Ademais, por se caracterizar muito flexível, isso também ajuda a explicar essa questão de ser o mais expressivo no transporte de cargas (Dias \& Ribeiro, 2013; Costa, Bartholomeu, Caixeta Filho, \& Rocha, 2016). Entretanto, Gudolle (2016) alerta que o modal rodoviário possui custos mais elevados quando comparado com o ferroviário. A seguir, na Figura 3 apresenta-se um comparativo entre os modais ferroviário e rodoviário divulgado pela Agência Nacional de Transportes Aquaviários [ANTAQ] (2011).

\begin{tabular}{|l|c|c|}
\hline \multicolumn{1}{|c|}{ Variáveis } & Ferroviário & Rodoviário \\
\hline Capacidade de carga & $\begin{array}{c}\text { 2,9 Comboios Hopper } \\
(86 \text { vagões })\end{array}$ & $\begin{array}{c}\text { 172 Carretas Bi-Trem } \\
\text { graneleiras }\end{array}$ \\
\hline Comprimento total (ocupação da via) & $1,7 \mathrm{~km}$ & $\begin{array}{c}3,5 \mathrm{~km} \\
\text { (26 km em movimento) }\end{array}$ \\
\hline Consumo de combustível (1 ton./1.000 km) & 10 litros & 96 litros \\
\hline $\begin{array}{l}\text { Emissão de monóxido de carbono (1 ton./1.000 } \\
\mathrm{km})\end{array}$ & 104 gramas & 219 gramas \\
\hline Eficiência energética (tons./hp) & $0,75(4$ x rodoviário) & 0,17 \\
\hline Custo logístico (US\$ 1.000 km/ton.) & 24 & 36 \\
\hline
\end{tabular}

Figura 3: Comparativo entre os modais ferroviário e rodoviário

*Nota: para unidades equivalentes de capacidade de carga

Fonte: Adaptado ANTAQ (2011).

Percebe-se na Figura 3 - sobre a capacidade de carga - que enquanto é necessário 2,9 Comboios do tipo Hopper (86 vagões) via ferrovia é preciso 172 Carretas do tipo Bi-Trem graneleiras para o transporte das mesmas unidades equivalentes pela rodovia. Acerca do consumo de combustível adotando como meio de transporte o ferroviário a diferença corresponde a $860 \%$ quando comparado com o modal rodoviário. Sob esse enfoque, conforme dados da Confederação Nacional do Transporte [CNT] (2018), observa-se na Figura 4 o consumo de óleo diesel para ambos os modais.

\begin{tabular}{|c|c|c|}
\hline Ano & Ferroviário & Rodoviário \\
\hline 2012 & 1,21 & 38,60 \\
\hline 2013 & 1,20 & 40,68 \\
\hline 2014 & 1,18 & 41,40 \\
\hline 2015 & 1,14 & 40,20 \\
\hline 2016 & 1,12 & 38,77 \\
\hline 2017 & 1,21 & 39,17 \\
\hline
\end{tabular}

Figura 4: Consumo de óleo diesel (em milhões de $\mathrm{m}^{3}$ )

* Atualmente, o óleo diesel comercializado no Brasil é o B10; ou seja, contém 10\% de biodiesel em sua mistura, conforme determinam a Lei Federal no 13.263/2016 e a Resolução CNPE nº 23, de 09/11/2017.

Fonte: Adaptado CNT (2018). 
Verifica-se no Quadro 3 que nos últimos seis anos o consumo de óleo diesel se manteve praticamente estável em cada modal - com exceção de 2012 (1,21 para 1,12 em 2016) no ferroviário - representando uma redução de 7,44\%. Todavia, o consumo médio de óleo diesel no período foi de 39,80 no modo rodoviário e de apenas 1,18 no transporte ferroviário. É oportuno frisar que tais dados têm impactos importantes. Por um lado, Arruda Júnior (2014) aponta que no modal rodoviário tendo o óleo diesel como principal combustível utilizado o custo com o frete já representa quase $40 \%$ no Brasil. Portanto, a despesa com óleo diesel é uma das mais pesadas para o referido setor (CNT, 2012). Por outro lado, as mudanças climáticas nos últimos anos vêm sendo frequentemente discutidas pelos mais variados canais da sociedade civil (Maciel, Barros Junior, \& Andreazzi, 2015), onde tais mudanças têm afetado a todos e são oriundas do aumento da concentração dos gases de efeito estufa (GEE) (Nunnenkamp \& Corte, 2017).

Nesse sentido, Arioli e Lindau (2014) citam que o setor de transportes está entre as principais fontes de emissão de GEE. Complementarmente, Drumm et al. (2014) afirmam que no país 32\% das emissões de carbono são decorrentes das atividades de transporte - esse é um número elevado na comparação com a média mundial - e isso ocorre em função do modal rodoviário que possui predomínio sobre os outros. Gonçalves (2012) pondera que o transporte no país tem uma dependência exagerada do modo rodoviário sendo notório que poderia vir a ser utilizado outros meios como no caso dos trens e barcas.

\section{Metodologia}

A metodologia utilizada neste artigo é baseada na Dinâmica de Sistemas possibilitando ao estudo criar modelos computacionais para analisar o comportamento dos sistemas ao longo do tempo, permitindo assim, a avaliação das consequências de nossas decisões. Chwif e Medina (2015) descrevem a modelagem computacional como uma apresentação de sistemas reais, possuindo grande importância para entender a complexidade do mundo real.

Um modelo de simulação consegue capturar com mais fidelidade as características de tempo, estado e natureza e a partir de softwares essas características capturadas são repetidas em um computador com o mesmo comportamento que o sistema real apresenta auxiliando, deste modo, no processo decisório (Chwif \& Medina, 2015). Conforme Andrade, Seleme, Rodrigues, \& Souto (2006), a modelagem computacional é uma das ferramentas do pensamento 
sistêmico que adicionam aprendizado ao processo e por meio da mesma constroem-se micromundos do sistema real.

Para a criação da modelagem neste trabalho foi utilizada à metodologia proposta por Law (2015) e consistiu das seguintes etapas: a etapa (I) representa o estudo exploratório em artigos científicos, relatórios técnicos, diálogos com stakeholders e observações do ambiente onde os dados foram coletados. Ressalta-se que os dados foram coletados em uma empresa privada localizada na região central do Rio Grande do Sul que realiza a coleta e o transporte dos RSU em sete municípios. Através desses dados, o objetivo de pesquisa foi especificado e estruturado. A etapa (II) apresenta o desenvolvimento da solução através da construção de modelos formais capazes de representar o problema (definição das variáveis e seus relacionamentos).

A implementação computacional da solução (etapa III), foi realizada com o auxílio do simulador Vensim ${ }^{\circledR}$ (Ventana Systems, 2016) da área de Dinâmica de Sistemas. A etapa (IV) é responsável pela verificação e avaliação da solução através de testes em laboratório e análise do comportamento histórico (com os dados que foram possíveis) para verificar se os resultados obtidos representam parte da realidade observada, bem como por meio da simulação de um experimento adotando nove cenários para tal. Além disso, também foram entrevistados gestores das áreas envolvidas para garantir uma maior fidedignidade ao estudo. Por fim, a pesquisa foi analisada na etapa (V) onde foram expostas as diferenças entre as possibilidades existentes.

\section{Desenvolvimento do modelo e experimento}

Melquíades (2015) salienta que tanto a coleta como o transporte dos RSU é um problema crítico em boa parte das cidades do Brasil. Conforme Souza e Guadagnin (2009), as etapas de coleta e transporte despendem entre $60 \%$ e $80 \%$ em termos de custos globais quando se trata do gerenciamento dos resíduos. Nesta pesquisa, foi simulada a logística de transporte dos RSU, cujo modelo proporcionará aos gestores comparar o transporte por trem e por caminhão. Sendo assim, tem-se que o modelo desenvolvido deverá reagir a diferentes fatores, tais como: o crescimento populacional, a média de geração de resíduos sólidos urbanos per capita e o custo do transporte.

Para a sua construção, foi necessário aprofundar o conhecimento acerca da área dos modais ferroviários e rodoviários. Para avaliar os dados coletados foi utilizado o relatório da ANTT (2013). Cabe frisar que no modal rodoviário existem vários tipos de caminhões com 
tamanho e capacidades diferentes. Deste modo, nesta pesquisa os caminhões responsáveis pela coleta dos RSU são classificados como caminhões leves, pois, segundo o relatório do Ministério do Meio Ambiente [MMA] (2014), os caminhões com capacidade de carregar entre 6 e 10 toneladas se enquadram nesta nomenclatura.

O consumo dos caminhões levou em conta a tonelada carregada diária além da distância percorrida, cujos dados foram coletados em relatórios como ANTT (2013), Associação Nacional dos Fabricantes de Veículos Automotores [ANFAVEA] (2014), (MMA, 2014), Petrobras (2018), e ainda, diretamente no banco de dados da empresa responsável pela coleta dos RSU na região aqui considerada para fins de análise. Os valores referentes às coletas internas e o envio até Santa Maria/RS (único aterro sanitário licenciado da região) estão expostos na Figura 5.

\begin{tabular}{|l|c|c|c|c|c|}
\hline \multicolumn{1}{|c|}{ Cidade } & $\mathbf{N}^{\mathbf{0}}$. Coletas & Envio Aterro & Diesel Gasto & Coleta Interna & Diesel Gasto \\
\hline Agudo & 6 por semana & $3403.2 \mathrm{~km}$ & 1361.28 litros & $500 \mathrm{~km}$ & 200 litros \\
\hline Cacequi & 6 por semana & $5952 \mathrm{~km}$ & 2380.80 litros & $480 \mathrm{~km}$ & 192 litros \\
\hline Restinga Seca & 6 por semana & $2827.2 \mathrm{~km}$ & 1130.88 litros & $493.4 \mathrm{~km}$ & 197.36 litros \\
\hline São Francisco & 6 por semana & $6672 \mathrm{~km}$ & 2668.80 litros & $515.6 \mathrm{~km}$ & 206.24 litros \\
\hline Faxinal & 3 por semana & $1406.4 \mathrm{~km}$ & 562.56 litros & $133.6 \mathrm{~km}$ & 53.44 litros \\
\hline Mata & 3 por semana & $1992 \mathrm{~km}$ & 796.80 litros & $109.8 \mathrm{~km}$ & 43.92 litros \\
\hline São Martinho & 2 por semana & $472 \mathrm{~km}$ & 188.80 litros & $42.8 \mathrm{~km}$ & 17.12 litros \\
\hline Total & N/C & 19321.6 & 9089.92 & 2275.2 & 910.08 \\
\hline
\end{tabular}

Figura 5: Dados da coleta mensal

Fonte: Empresa responsável coleta dos RSU na região estudada (2018).

Para o ferroviário, a ANTT utiliza dados providos por cada concessionária de ferrovia para informar a distância média percorrida de um vagão a cada mês de operação (ANTT, 2013; América Latina Logística [ALL], 2013). Conforme Novo (2016), a projeção do volume de carga para o modal ferroviário ocorre de modo similar à projeção rodoviária, ou seja, "ambas consideram a distância média, frota de vagões e capacidade média do vagão, sendo o valor ajustado por um fator de carregamento para chegar à quantidade final de carga transportada (p. 40). Atualmente, as linhas para o transporte dos RSU estão desativadas, mas acompanham o trajeto do modal rodoviário.

Há dois modos para medir o consumo do transporte pelo modal ferroviário: (1) Tonelada Quilômetro Bruta (TKB) que é estipulada a "quantidade de toneladas brutas (soma das toneladas do produto com a tara do vagão) transportadas multiplicadas pela quilometragem percorridas pelas mesmas" (Santos, 2012, p. 56); e (2) pela Tonelada Quilômetro Útil (TKU) que se refere "a quantidade de toneladas úteis transportadas multiplicadas pela quilometragem percorrida pelas mesmas" (ANTT, 2016, p. 13). Neste artigo, foi usado somente o TKU 
levando-se em conta que o trem partirá apenas carregado, ou seja, não será analisado o transporte do trem com os vagões vazios. Para saber o valor médio do consumo do transporte em TKU e também seu comportamento anual foi utilizada a seguinte Equação(i):

Valor Médio do Consumo $=$ Frota $($ vagões $) x$ percurso médio por vagão $(\mathrm{km}) x$ capacidade do vagão( $t$ ) $x$ fator de carregamento $(i)$

Os dados das variáveis descritas na Equação(i) estão expostos no relatório anual da ANTT (2013). A partir da equação supracitada, entende-se que o percurso médio por vagão utiliza dados providos por cada concessionária de ferrovia para informar a distância média percorrida de um vagão a cada mês de operação. A capacidade útil do vagão é determinada por cada concessionária - já que os trechos são diferentes - e para a frota de vagões é informado nos relatórios da ANTT à quantidade de vagões em operação por concessionária e, por fim, o fator de carregamento é representado no relatório da ANTT por dados mensais por concessionária (medidos em litros por TKU). Após a compreensão destas variáveis apresentadas gerou-se a Figura 6, onde consta a variação anual que foi usada na simulação.

\begin{tabular}{|c|c|c|}
\hline \multirow{2}{*}{ Ano } & \multicolumn{2}{|c|}{ Taxa } \\
\cline { 2 - 3 } & Nascimento & Mortalidade \\
\hline $\mathbf{2 0 1 9}$ & 11.20 & 7.08 \\
\hline $\mathbf{2 0 2 0}$ & 11.3 & 7.17 \\
\hline $\mathbf{2 0 2 1}$ & 10.83 & 7.27 \\
\hline $\mathbf{2 0 2 2}$ & 10.72 & 7.37 \\
\hline $\mathbf{2 0 2 3}$ & 10.56 & 7.48 \\
\hline $\mathbf{2 0 2 4}$ & 10.4 & 7.6 \\
\hline $\mathbf{2 0 2 5}$ & 10.24 & 7.72 \\
\hline $\mathbf{2 0 2 6}$ & 10.15 & 7.85 \\
\hline $\mathbf{2 0 2 7}$ & 9.99 & 7.99 \\
\hline $\mathbf{2 0 2 8}$ & 9.81 & 8.13 \\
\hline $\mathbf{2 0 2 9}$ & 9.97 & 8.29 \\
\hline
\end{tabular}

Figura 6:Taxas I

Fonte: Elaborado pelos autores a partir dos dados do IBGE (2016).

Para a simulação foi adotado o planejamento por cenário e para este estudo foram gerados três cenários. Suas diferenças, as taxas e as variáveis formadoras de cada cenário apresentamse descritas na próxima seção. 


\subsection{Cenários}

O futuro é inerentemente incerto e desconhecido, porém, com base no conhecimento podem-se considerar futuros plausíveis. Através do planejamento por cenários torna-se possível analisar diferentes projeções futuros para tomar a melhor decisão. Sua finalidade é construir diversos cenários plausíveis e com base neles definir estratégias robustas para aplicação no presente e, consequentemente, testar o modelo e as hipóteses geradas (Andrade et al., 2006).

Para a construção dos cenários foi necessário compreender a logística da coleta de RSU da região estudada, além de compreender o crescimento populacional e, por sua vez, a geração do resíduo per capita. Pela dinâmica das inter-relações entre as variáveis geram-se padrões de comportamento futuro que são, na verdade, cenários que se configurarão caso aquelas forças continuarem atuando tal como mapeados. Para realizar o mapeamento foram utilizados dados de diferentes plataformas, tais como: relatórios do Instituto Brasileiro de Geografia e Estatística [IBGE] (2008), Agência Nacional do Petróleo, Gás Natural e Biocombustíveis [ANP] (2016) dentre outros estudos. Para analisar a proposta do artigo geraram-se três cenários, a saber:

- Cenário Atual: responsável por medir o comportamento atual do sistema. Os dados utilizados neste cenário tentarão representar a coleta dos resíduos sólidos mais próximos da realidade;

- Cenário Modal: simulará o transporte do RSU em 40\% pelo modal ferroviário, utilizando as linhas ainda ativas; e

- Cenário Modal Otimista: simulará o transporte do RSU pelo modal ferroviário utilizando as linhas ativas e inativas, transportando $50 \%$ da totalidade dos resíduos gerados pela população da região.

O combustível utilizado na coleta é o diesel derivado do petróleo. De acordo com a Petrobras (2018), os combustíveis derivados de petróleo são commodities e possuem seus preços vinculados aos mercados internacionais, cujas cotações variam de forma diária tanto para cima como para baixo. Além disso, acrescenta ainda que o preço do litro comercializado pelas distribuidoras possui como base o preço de paridade de importação, composto pelas cotações internacionais destes produtos mais os custos que importadores teriam (como transporte e taxas portuárias). 
A paridade é algo necessário, pois o mercado do Brasil de combustíveis é aberto à livre concorrência, oferecendo as distribuidoras à opção de importar os produtos. Ademais, o preço leva em conta uma margem que cobre os riscos (como volatilidade do câmbio e dos preços) (Petrobras, 2018). Os preços médios informados atendem a média aritmética nacional dos preços à vista, livre de encargos e livre de tributos, praticados na modalidade de venda padrão nos inúmeros pontos de fornecimento, com variações ao longo do território brasileiro, para mais ou para menos em relação à média (Petrobras, 2018). No Quadro 6 observa-se a variação do preço médio do litro do diesel utilizada.

Os dados obtidos referentes à coleta dos RSU pelo modal rodoviário foram obtidos diretamente com a empresa responsável e o rendimento dos caminhões foi validado em entrevistas com stakeholders da área. Para o modal ferroviário foram utilizados artigos técnicos e relatórios governamentais. Os dados sobre à população e suas taxas foram retiradas de planilhas, gráficos e projeções disponibilizados pelo IBGE (2016) e além destes dados outros estudos foram adotados para embasar as demais variáveis do modelo, tais como: Pidd (1998), Ford (2009), Strauss (2010), Simonetto, Rodrigues, Dalmolin, \& Modro (2014), Simonetto, Putnik, Rodrigues, Alves, \& Castro (2016) etc. Já para a geração de RSU foi utilizado o relatório da Associação Brasileira de Empresas de Limpeza Pública e Resíduos Especiais [ABRELPE] (2016).

Para contemplar a análise ambiental do modelo será estudada a emissão de dióxido de carbono $\left(\mathrm{CO}_{2}\right)$, o qual varia de acordo com o combustível consumido. Nesta pesquisa, ambos os modais fazem uso do óleo diesel para locomoção e para diferenciar as emissões de cada modal por quilômetro foram adotados dados divulgados pela ANTT (2013). Os dados utilizados nos cenários foram tabulados e estão apresentados na Figura 7.

\begin{tabular}{|l|c|c|c|}
\hline \multicolumn{1}{|c|}{ Variável } & \multicolumn{2}{c|}{ Cenário } & Modal \\
\cline { 2 - 4 } & Atual & 60 & 50 \\
\hline Tx. RSU Caminhão & 100 & 10000 & 10000 \\
\hline Capacidade Caminhão(Kg) & 10000 & 376.8 & 376.8 \\
\hline Média RSU & 376.8 & 40 & 50 \\
\hline Tx. RSU Trem & 0 & 5.6 & 5.6 \\
\hline Rendimento Médio Motor(Km/l) & 5.6 & 15000 & 12500 \\
\hline Distância(Km) & 25000 & $0.08 \% \mathrm{a} . \mathrm{a}$ & $0.08 \% \mathrm{a} . \mathrm{a}$ \\
\hline Variação Preço Diesel(I) & $0.08 \% \mathrm{a} . \mathrm{a}$ & $\mathrm{R} \$ 2.99$ & $\mathrm{R} \$ 2.99$ \\
\hline Preço Combustível Inicial & $\mathrm{R} \$ 2.99$ & 80729 & 80729 \\
\hline Habitantes Inicial & 80729 & 0,0079 & 0,0079 \\
\hline CO2 modal Rodoviário(Kg/TKU) & 0,0079 & 0,0012 & 0,0012 \\
\hline CO2 modal Ferroviário $\mathbf{( K g / T K U ) ~}$ & 0,0012 & & \\
\hline
\end{tabular}

Figura 7:Taxas II

Fonte: Autores (2018). 
Para a definição das variáveis componentes do modelo foram utilizados os dados supracitados além da lógica obtida pelos pesquisadores através do conhecimento adquirido a partir de observações, aprofundamento bibliográfico e estudo em documentos públicos na área de RSU. Na próxima seção será apresentado o modelo e suas relações.

\subsection{Modelos desenvolvidos}

Para atender ao objetivo proposto neste artigo foram gerados dois modelos: (1) com o foco voltado para a análise financeira; e (2) contemplando a parte ambiental. Sendo assim, o modelo computacional desenvolvido para investigar o viés financeiro é composto de uma variável de estoque, duas variáveis de fluxo, dezesseis variáveis auxiliares e uma variável do tipo "shadow" chamada time, possibilitando a indicação da unidade de tempo durante a execução no software Vensim $^{\circledR}$.

Tendo em vista uma melhor compreensão foi desenvolvido uma estrutura de feedback que, para Strauss (2010), as relações de feedback são as relações causais entre as variáveis e são representadas por enlaces entre estas variáveis. Neste estudo existem três variáveis centrais (habitantes, RSU e Custo Transporte RSU) que ao serem afetadas, positivamente ou negativamente, acarretam diferentes mudanças no sistema, podendo afetar diretamente o resultado do modelo desenvolvido.

Logo, quando a quantidade de mortes e nascimentos for positiva, o somatório de habitantes será maior, consequentemente, a geração de RSU acompanhará tal acrescimento, encarecendo assim, o transporte do resíduo. Porém, se qualquer uma das variáveis (mortes/nascimentos) for negativa, acontecerá o fluxo contrário ao mencionado anteriormente. Assim, visualiza-se na Figura 8 a estrutura utilizada para construir a lógica do modelo computacional desta pesquisa. 


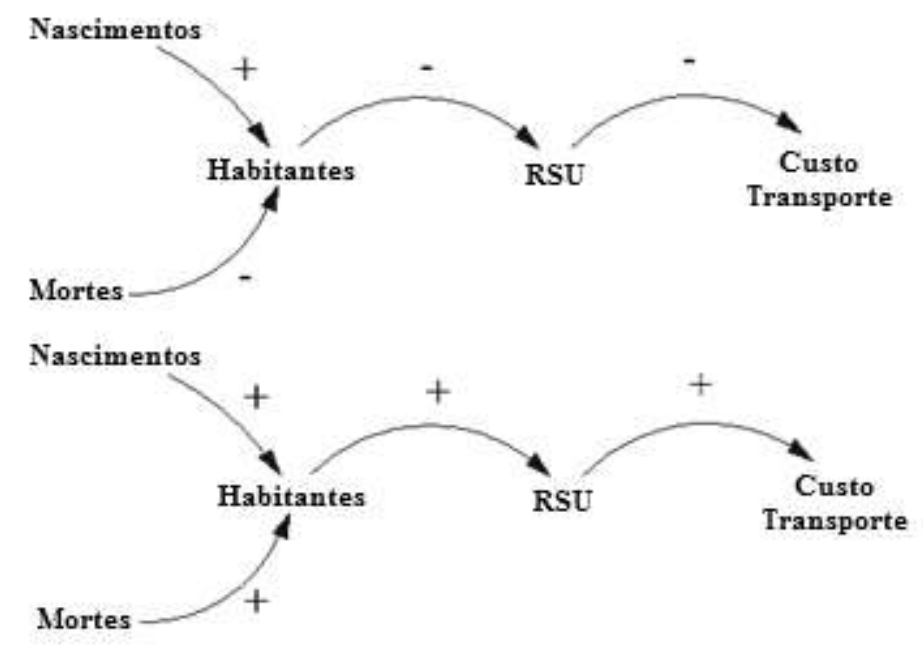

Figura 8. Estrutura de feedback

Fonte: Autores (2018).

A "Taxa de Nascimento" e a "Taxa de Mortalidade" influenciam diretamente os fluxos de entrada e saída ("Nascimentos" e "Mortes") da variável de estoque "Habitantes", esta interação determinam a população total nos anos simulados dos municípios estudados. Para isso, foi adotado o estudo de Simonetto et al. (2014) como referência para construção da lógica populacional, utilizando o modelo de taxa de crescimento natural ou vegetativo (total de nascimentos - total de mortes), a qual corresponde à única forma possível de crescimento ou redução da população mundial. O total de RSU da região gerado é o resultado da multiplicação da variável auxiliar "Média $\boldsymbol{R S U}$ " pelo total da população, valor armazenado na variável de estoque "Habitantes".

O total dos resíduos gerados (em tonelada) será dividido em dois transportes, cuja divisão é estabelecida nas variáveis “Tx $R S U$ Caminhão" e "Tx $R S U$ Trem”. Com elas, será possível criar os cenários utilizados neste estudo e possibilitará ao modelador e aos gestores da área criar novos cenários diferentes, podendo testar diferentes divisões. A quantidade de caminhões necessários para suprir o transporte do RSU é calculado pela Equação 3 exibida na Figura 7 e é representada no modelo pela variável "Caminhões Coleta".

O consumo da coleta pelo modal rodoviário é representado pela Equação 4 (Figura 7) e possui a variável “Consumo Caminhão" representada no modelo. Ela é resultado da interação entre as variáveis "Rendimento Médio Motor" e "Distância", que simulam a média do consumo por quilômetro dos diferentes modelos de caminhões utilizados pela empresa coletora. O consumo do modal ferroviário (“Consumo Trem”) é a representação da interação entre as 
variáveis "MédiaTKU", “Tx RSU" e "Trem Total Rsu” e está exposto na Equação 5 mostrada na Figura 8. Para suprir o objetivo deste artigo gerou-se a variável "Custo Coleta RSU", que reúne os dados armazenados do consumo dos modais rodoviário e ferroviário além da variação do Preço do Diesel ("Variação Diesel"), cujos dados adotados foram exibidos na Figura 7 visto anteriormente. O modelo responsável pelo custo da coleta é exposto na Figura 9.

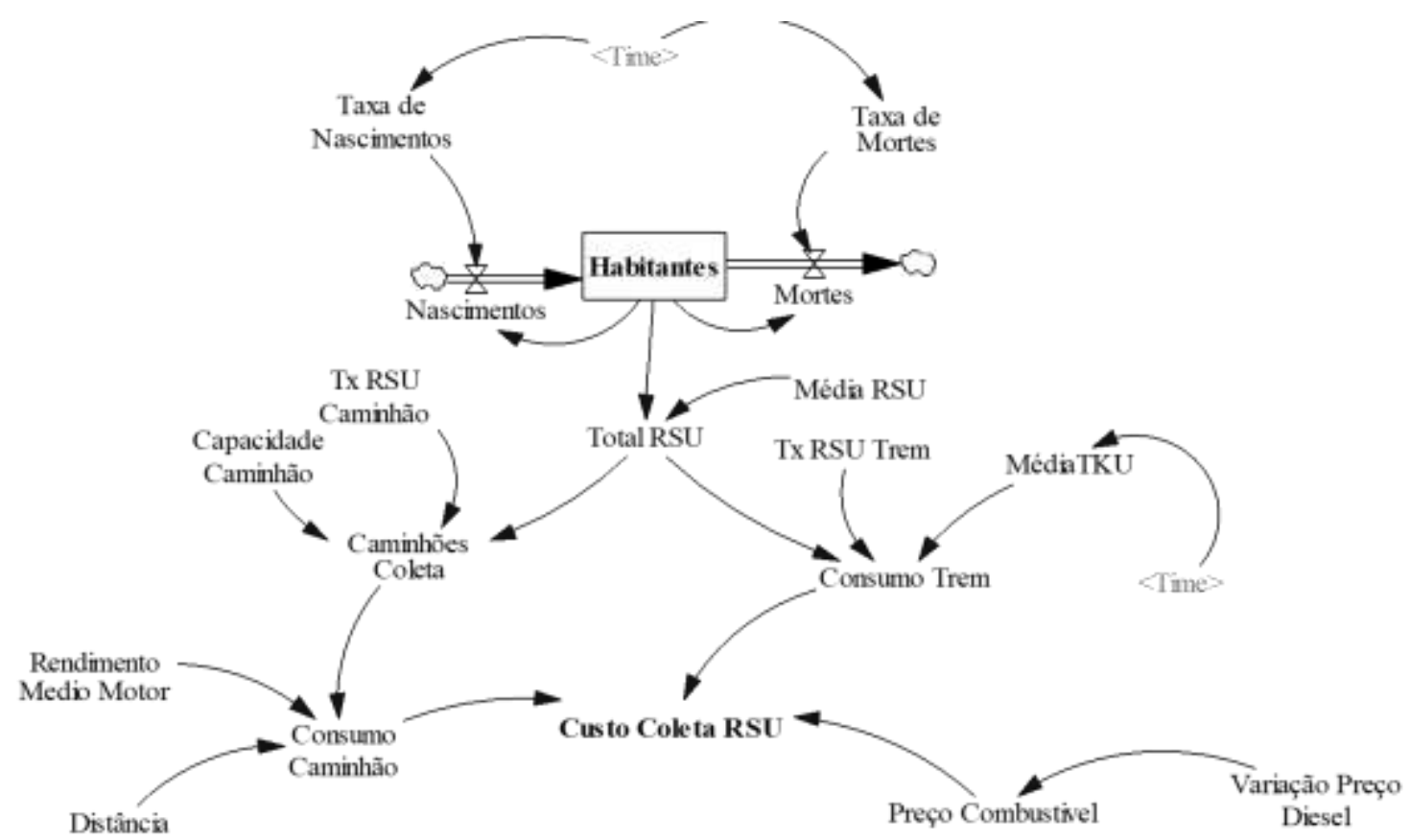

Figura 9. Modelo financeiro

Fonte: Autores (2018).

O modelo responsável por armazenar o comportamento ambiental está exposto na Figura 10 e é composto de uma variável de estoque ("Total Emissãa"), quatro variáveis auxiliares ("CO2 Caminhão", "CO2 Trem", "EMISSÃO CO2 Caminhão" e " EMISSÃO CO2 Trem"), três shadow variables ("Tx RSU Caminhão", "Total RSU" e "Tx RSU Trem") e para inserir os dados de entrada na variável de estoque gerou-se duas variáveis do tipo "arrow”, que replicarão os dados armazenados nas variáveis auxiliares "EMISSÃO CO2 Caminhão" e " EMISSÃO CO2 Trem". Vale destacar que as variáveis shadow já pertencem ao modelo apresentado na Figura 8, possibilitando assim, que os dados inseridos repliquem nos dois modelos igualmente. 


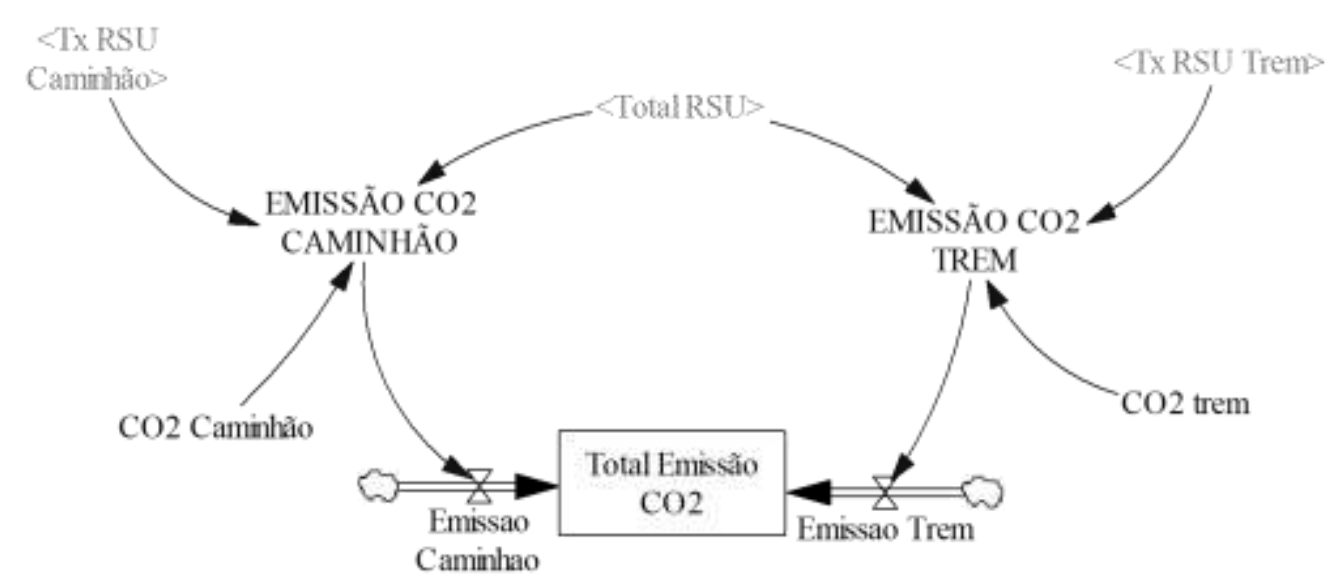

Figura 10. Modelo ambiental Fonte: Autores (2018).

O modelo de equações segue exposto na Figura 11, cujas equações foram inseridas no software Vensim $^{\circledR}$ e são responsáveis pelos resultados da simulação do modelo computacional desenvolvido.
(1) Habitantes = Nascimentos-Mortes
(2) Total RSU = Habitantes*Média RSU
(3) Caminhões Coleta $=($ Total RSU*Tx RSU Caminhão $) /$ Capacidade Caminhão
(4) Consumo Caminhão $=($ Caminhões Coleta*Distância $) /$ Rendimento Médio Motor
(5) Consumo Trem $=($ Total RSU*Tx RSU Trem $) *$ MédiaTKU
(6) Preço Combustível $=2.99 *$ Variação Preço Diesel
(7) Custo Coleta RSU = (Consumo Caminhão+Consumo Trem $) *$ Preço Combustível
(8) Emissão CO2 Caminhão = (Total RSU*Tx RSU Caminhão $)^{*} \mathrm{CO} 2$ Caminhão
(9) Emissão CO2 Trem $=($ Total RSU $*$ Tx RSU Trem $) * \mathrm{CO} 2$ Trem
(10) Total Emissão CO2 = Emissão CO2 Caminhão * Emissão CO2 Trem

Figura 11: Modelo de equações

Fonte: Autores (2018).

Após a definição de todas as equações e suas relações o modelo foi simulado. Sendo assim, o seu experimento encontra-se descrito na próxima seção.

\subsection{Experimento do modelo computacional}

Definidos os três cenários tornou-se possível simular a proposta do modelo desenvolvido no simulador Vensim ${ }^{\circledR}$ (Ventana Systems, 2016) em um computador com processador Pentium Core i3 e 4GB de memória RAM. O tempo de execução da simulação foi na ordem de centésimos de segundos e o horizonte de tempo simulado no experimento foi de onze anos. Entretanto, a configuração dessa variável fica a cargo do projetista/usuário, pois esta depende da análise a ser feita. 
Com o modelo desenvolvido, diversas análises podem ser executadas e no atual estudo foram selecionadas as que pareceram ser mais relevantes no entendimento dos autores e dos stakeholders participantes do estudo, são elas: o crescimento populacional e sua relação com a geração de RSU e, como consequência, o custo do transporte deste resíduo até o aterro sanitário localizado em Santa Maria/RS. É importante ressaltar que o modelo é aberto a novas configurações, sendo toda e qualquer análise do tipo “what if” de simples e fácil utilização, pois quando da modificação nos valores das taxas e variáveis, novos resultados são gerados para análise dos usuários (Simonetto et al., 2016).

A primeira análise a ser desenvolvida com o uso do modelo refere-se à quantidade de habitantes na região estudada, assim, em 2018, era de 80.040 pessoas e no ano de 2019 há um acréscimo de 689 pessoas. Nos onze anos simulados houve uma variação média de aproximadamente 2,89\% chegando em 107.977 habitantes no ano de 2029. Sabendo a possível população da região assimilando com a média da geração de RSU per capita tornou-se possível estimar qual será a geração de lixo per capita durante onze anos e a Figura 4 apresenta esta projeção. Sendo assim, no ano de 2019 já será produzido cerca de 30.000 toneladas de lixo, chegando em 40.000 toneladas em 2029, tendo uma média de geração de RSU por ano de aproximadamente 35.000 toneladas. Verifica-se no Quadro 8 o crescimento populacional nos onze anos de análise além da geração de RSU da região estudada.

\begin{tabular}{|c|c|c|}
\hline Ano & Habitantes & Resíduo Sólido Urbano (Kg) \\
\hline 2019 & 80.729 & 8.173 .000 \\
\hline 2020 & 84.055 & 8.509 .730 \\
\hline 2021 & 87.526 & 8.861 .180 \\
\hline 2022 & 90.642 & 9.176 .640 \\
\hline 2023 & 93.679 & 9.484 .060 \\
\hline 2024 & 96.667 & 9.786 .600 \\
\hline 2025 & 99.490 & 10.072 .400 \\
\hline 2026 & 102.117 & 10.338 .300 \\
\hline 2027 & 104.598 & 10.589 .500 \\
\hline 2028 & 106.836 & 10.816 .100 \\
\hline 2029 & 107.977 & 11.013 .000 \\
\hline
\end{tabular}

Figura 12: Habitantes e RSU

Fonte: Autores (2018).

O custo para transportar o resíduo urbano visto na Figura 4 está representado na Figura 5, a seguir, onde se comparou os cenários com transporte pelo modal rodoviário e ferroviário. O Cenário Atual - que representa a coleta via modal rodoviário (meio de transporte usual nos dias de hoje) - é o transporte mais caro: chegando a custar R \$ 1.038.000,00 ao ano, 
totalizando em 2029 cerca de $\mathrm{R} \$$ 105.154.007. O cenário com melhor desempenho financeiro é o Cenário Modal Otimista, que economizará cerca de $\mathrm{R} \$ 7$ milhões ao ano se comparado ao cenário com pior rendimento financeiro. O Cenário Modal também apresentará uma economia quando comparado ao Cenário Atual podendo gerar, aproximadamente, $\mathrm{R} \$ 4$ milhões ao ano.

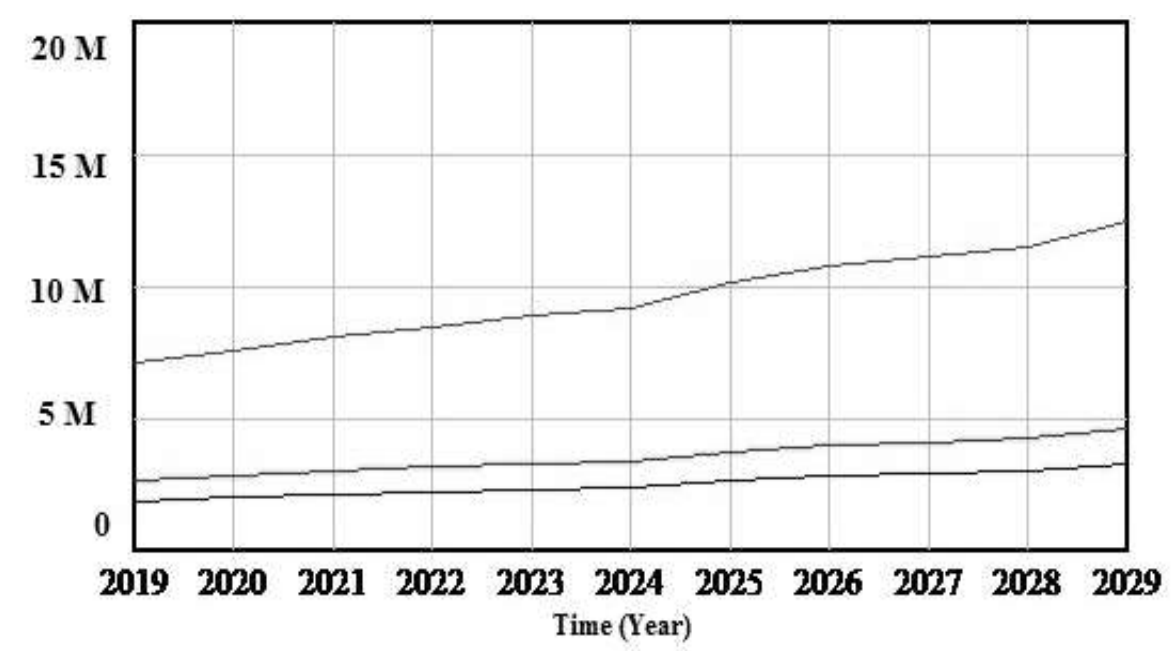

Custo Coleta RSU: Cenário Modal Otimista

Custo Coleta RSU: Cenário Modal

Custo Coleta RSU: Cenário Atual

Figura 13. Custo total da coleta dos resíduos sólidos urbanos Fonte: Autores (2018).

A poluição do ar é um dos maiores problemas ambientais no mundo, sendo considerado um fator preocupante tanto para a atualidade como para as próximas gerações (Instituto Estadual do Ambiente [INEA], 2012). Diante disso, a segunda análise do modelo é referente à emissão do dióxido de carbono $\left(\mathrm{CO}_{2}\right)$ resultante da combustão completa do carbono, logo, a Figura 6 apresenta a simulação realizada. Nota-se que o Cenário Modal Otimista é o que possui o menor índice de emissão de $\mathrm{CO}_{2}$, totalizando em onze anos aqui simulados, aproximadamente, 435 toneladas. Isso representa 321 toneladas a menos que o cenário com o maior índice de emissão (Cenário Atual), pois em 2029 emitirá até 756 toneladas de $\mathrm{CO}_{2} . \mathrm{O}$ Cenário Modal também apresenta menor emissão de $\mathrm{CO}_{2}$ quando comparado ao Cenário Atual, ele emitirá aproximadamente 500 toneladas, cerca de 256 toneladas a menos que o Cenário Atual. 


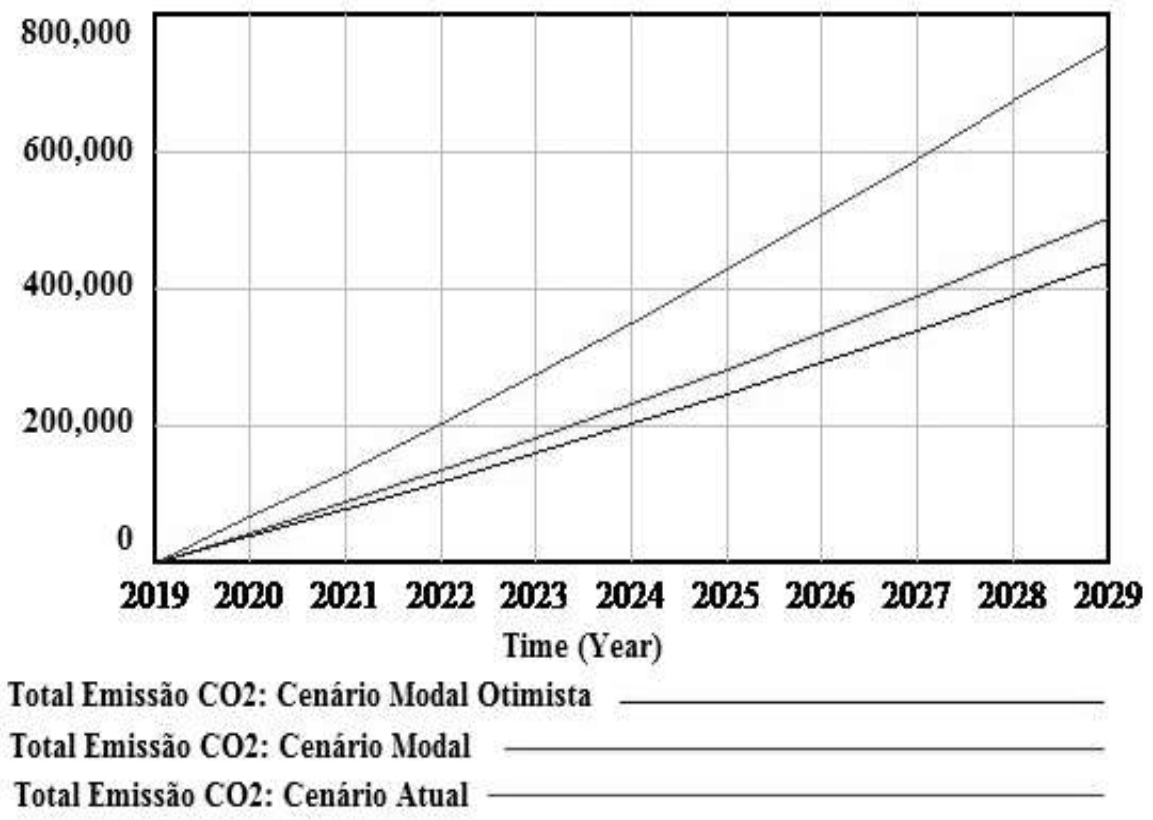

Figura 14. Total de emissão de $\mathrm{CO}_{2}$ Fonte: Autores (2018).

Observa-se pelas simulações geradas neste trabalho que há uma grande diferença em termos financeiros e ambientais entre os modais ferroviários e rodoviários. Isso além de demonstrar a importância da valorização das ferrovias, também se apresenta como outra opção aos gestores para fins de transporte do lixo gerado nos municípios estudados, uma vez que o modal ferroviário não substitui o modal rodoviário, mas sim, poderia vir a ser melhor explorado em razão dos benefícios oriundos da sua adoção.

\section{Considerações finais}

O surgimento contínuo de novas tecnologias no mercado, o processo de urbanização e o aumento do poder aquisitivo dos indivíduos são algumas das características presentes na sociedade contemporânea. Logo, tais fatores alteram e moldam as atuais práticas de consumo o que faz com que as discussões em torno dos RSU gerados sejam cada vez mais trazidas em seminários, fóruns, palestras, bem como expostas em trabalhos e publicações que abordem tal problemática.

A questão é que os RSU se tornaram um problema tanto no Brasil com em outras partes do mundo e além de gastos financeiros significativos tem ainda toda a parte dos danos ambientais causados pelo descarte inadequado desses resíduos no meio ambiente. Consequentemente, todos são afetados e isso exige com que se pense em meios de como 
amenizar esses problemas no sentido de busca de alternativas visando reduzir tanto os impactos negativos financeiros como os impactos ambientais oriundos dos RSU.

Deste modo, considerando a proposta deste artigo e dentre as análises realizadas, verificou-se nos onze anos simulados que o número de habitantes na região considerada para fins de estudo atinge um total de 107.977 no ano de 2029. A partir disso, tornou-se possível fazer uma estimativa da geração de lixo per capita no período, onde se constatou que a média de geração de RSU por ano será de aproximadamente 35.000 toneladas.

Quanto aos cenários simulados, observou-se que o Modal Otimista obteve o melhor desempenho financeiro - economizando cerca de $\mathrm{R} \$ 7$ milhões de reais - se comparado com o que apresentou o pior rendimento em termos financeiro. Ademais, investigando a parte ambiental, averiguou-se que Cenário Modal Otimista é o que apresentou o menor índice de emissão de $\mathrm{CO}_{2}$ no período simulado - aproximadamente, 435 toneladas - um total de 320,955 toneladas a menos no comparativo com o cenário com o maior índice de emissão.

No mais, a partir da pesquisa realizada é notável, visto de uma perspectiva financeira, que há uma grande diferença existente entre os modais rodoviário e ferroviário no transporte dos RSU. Ao findar este estudo, espera-se que o mesmo tenha contribuído para que os gestores e os governantes busquem novas opções diante do problema enfrentado com os RSU e, ao mesmo tempo, consigam encontrar meios de usufruir das vantagens proporcionadas pelo modal ferroviário.

Para isso, é necessário uma retomada de investimentos neste modal com o devido planejamento para que ao longo do tempo seja possível reverter à situação vivenciada hoje - a dependência excessiva das rodovias para o transporte de cargas - e se tenha uma infraestrutura adequada. No mais, acredita-se que as discussões em torno desta temática não se esgotam aqui. Sendo assim, como recomendação para futura pesquisa, indica-se uma investigação que contemple toda a parte ambiental levando em conta os benefícios que poderiam ser alcançados com a retomada das ferrovias no setor de transporte no Brasil.

\section{Referências}

Abrelpe - Associação Brasileira de Empresas de Limpeza Pública e Resíduos Especiais. (2016). Panorama dos resíduos sólidos no Brasil-2016. Recuperado em 19 junho, 2018, de http://www.mpdft.mp.br/portal/pdf/comunicacao/junho_2018/panoramaanexos2016.pdf.

All - América Latina Logística. (2013). Os setores ferroviário e rodoviário. Recuperado em 11 junho, 2018, de http://ri.all-logistica.com/conteudo_pt.asp?idioma=0\&conta=28\&tipo=275. 
Andrade, A. L., Seleme, A., Rodrigues, L. H., \& Souto, R. (2006). Pensamento sistêmico: caderno de campo: o desafio da mudança sustentada nas organizações e na sociedade. Porto Alegre: Bookman.

Anfavea - Associação Nacional dos Fabricantes de Veículos Automotores. (2014). Anuário da Indústria Automobilística Brasileira. Recuperado em 11 junho, 2018, de http://www.anfavea.com.br/anuario.html.

Anp - Agência Nacional do Petróleo, Gás Natural e Biocombustíveis. (2016). Boletim Anual de Preços 2016: preços do petróleo, gás natural e combustíveis nos mercados nacional e internacional. Rio de Janeiro: ANP.

Antaq - Agência Nacional de Transportes Aquaviários. (2011). Recuperado em 26 abril, 2018, de http://portal.antaq.gov.br/index.php/eventos/2011-2/ii-seminario-portos-e-vias-navegaveisum-olhar-sobre-a-infraestrutura.

Antt - Agência Nacional de Transportes Terrestres. (2013). Acompanhamento das concessões ferroviárias: relatório anual. Brasília: Ministério dos Transportes.

. (2016). Programa de Exploração Ferroviária (PEF). Recuperado em 05 junho, 2018, de http://www.antt.gov.br/backend/galeria/arquivos/caderno_de_engenharia_anexo_iii.pdf.

(2017). Mapa do sistema ferroviário nacional. Recuperado em 19 setembro, 2017, de http://appweb2.antt.gov.br/carga/ferroviario/ferroviario.asp.

Arioli, M., \& Lindau, L. A. (2014, novembro). Mecanismos de mitigação de gases de efeito estufa no transporte urbano. Anais do Congresso Nacional de Pesquisa e Ensino em Transporte, Curitiba, PR, Brasil, 28.

Arruda Júnior, J. da S. (2014). Desenvolvimento de um método para redução do consumo de combustivel no transporte rodoviário de cargas: capacitação, aplicações de torque e telemetria para veículos pesados. Dissertação de mestrado, Universidade de Brasília, Brasília, DF, Brasil.

Ballou, R. H. (2006). Gerenciamento da cadeia de suprimentos: logística empresarial. (5a ed.). Porto Alegre: Bookman.

Bartholomeu, D. B., \& Caixeta Filho, J. V. (2008). Impactos econômicos e ambientais decorrentes do estado de conservação das rodovias brasileiras: um estudo de caso. Revista de Economia e Sociologia Rural, 46(3), 703-738.

Castiglioni, J. A. de M., Pigozzo, L. (2014). Transporte e distribuição. São Paulo: Érica.

Chwif, L., \& Medina, A. C. (2015). Modelagem e simulação de eventos discretos: teoria e aplicação. (4a ed.). Rio de Janeiro: Elsevier.

Cnt - Confederação Nacional de Transporte. (2012). Os impactos da má qualidade do óleo diesel brasileiro. Brasília: CNT.

(2013). O sistema ferroviário brasileiro. Brasília: CNT.

(2018). Boletim estatístico. Recuperado em 25 abril, 2018, de http://cms.cnt.org.br/Imagens\%20CNT/BOLETIM\%20ESTAT\%C3\%8DSTICO/BOLETIM\%20 ESTAT\%C3\%8DSTICO\%202018/Boletim\%20Estat\%C3\%ADstico\%20-\%2001\%20$\% 202018$.pdf. 
Colavite, A. S., \& Konishi, F. (2015, outubro). A matriz do transporte no Brasil: uma análise comparativa para a competitividade. Anais do Simpósio de Excelência em Gestão e Tecnologia, Resende, RJ, Brasil, 12.

Costa, E. L., Bartholomeu, D. B., Caixeta Filho, J. V., \& Rocha, F. V. da. (2016, dezembro). Estudo sobre a mensuração do consumo de combustíveis em agentes do setor de transportes terrestres de cargas. Anais do Encontro Internacional sobre Gestão Empresarial e Meio Ambiente, São Paulo, SP, Brasil, 18.

Deus, R. M., Battistelle, R. A. G., \& Silva, G. H. R. (2015). Resíduos sólidos no Brasil: contexto, lacunas e tendências. Revista Engenharia Sanitária e Ambiental, 20(4), 685-698.

Dias, A. C. S., \& Ribeiro, M. M. (2013). Um estudo sobre a infraestrutura existente no Brasil para o transporte de cargas. Revista Intellectus, IX (23), 42-64.

Drumm, F. C., Gerhardt, A. E., Fernandes, G. D., Chagas, P., Sucolotti, M. S., \& Kemerich, P. D. da C. (2014). Poluição atmosférica proveniente da queima de combustíveis derivados do petróleo em veículos automotores. Revista Eletrônica em Gestão, Educação e Tecnologia Ambiental, 18(1), 6678.

Faria, A. C. de, \& Costa, M. de F. G. da. (2015). Gestão de custos logísticos: custeio baseado em atividades (ABC), balanced scorecard (BSC), valor econômico agregado (EVA). São Paulo: Atlas.

Ford, A. (2009). Modeling the environment. (2a ed.). Washington: Island Press.

Franzoni, A. M. B., \& Freitas, S. M. M. de. (2005, novembro). Logística de transporte internacional. Anais do Simpósio de Engenharia de Produção, Bauru, SP, Brasil, 11.

Frota, A. J. A., Tassigny, M. M., Bizarria, F. P. de A., \& Oliveira, A. G. de. (2015). Implantação de um sistema de coleta seletiva: aspectos legais e de sustentabilidade. Revista Gestão \& Sustentabilidade Ambiental, 4(1), 129-155.

Gomes, C. F. S., \& Ribeiro, P. C. C. (2004). Gestão da cadeia de suprimentos integrada à tecnologia da informação. São Paulo: Pioneira Thomson Learning.

Gonçalves, J. M. F. (2012). Cenários possíveis para o transporte de açúcar e de contêineres para o Porto de Santos visando à redução das emissões de gases de efeito estufa. Tese de doutorado, Universidade Metodista de Piracicaba, Santa Bárbara D’Oeste, SP, Brasil.

Gouveia, N. (2012). Resíduos sólidos urbanos: impactos socioambientais e perspectiva de manejo sustentável com inclusão social. Ciência \& Saúde Coletiva, 17(6), 1503-1510.

Gudolle, M. F. (2016). Os custos logísticos da soja em grãos: estudo de caso em uma empresa cerealista no município de Cruz Alta-RS. Dissertação de mestrado, Universidade de Cruz Alta, Cruz Alta, RS, Brasil.

Ibge - Instituto Brasileiro de Geografia e Estatística. (2008). Pesquisa Nacional de Saneamento Básico - 2008. Recuperado em 12 maio, 2018, de https://ww2.ibge.gov.br/home/estatistica/populacao/condicaodevida/pnsb2008/default.shtm.

. (2016). Taxas brutas em 2016: Brasil em síntese. Recuperado em 19 junho, 2018, de https://brasilemsintese.ibge.gov.br/populacao/taxas-brutas-de-natalidade.html.

Inea - Instituto Estadual do Ambiente. (2012). Cálculo de emissões para a frota de veículos brasileira. Recuperado em $20 \quad$ julho, $2018, \quad$ de http://www.mma.gov.br/images/arquivo/80060/GT\%20Inventarios/Breve\%20- 
$\% 20$ Calculo $\% 20 \mathrm{de} \% 20$ Emissoes $\% 20$ para $\% 20$ a $\% 20$ Frota $\% 20 \mathrm{de} \% 20$ Veiculos\%20Brasileira $\% 20$ Lemma_UFPR.pdf.

Law, A. M. (2015). Simulation modeling and analysis. (5a ed.). Porto Alegre: McGraw-Hill.

Maciel, M. A. D., Barros Junior, C., \& Andreazza, M. A. (2015, novembro). Levantamento de emissões de gases de efeito estufa no transporte de materiais de uma construção civil em Maringá/PR. Anais do Encontro Internacional de Produção Científica Unicesumar, Maringá, PR, Brasil, 9.

Magalhães, E., Santos, A. G., Elia, B., \& Pinto, G. (2013). Gestão da cadeia de suprimentos. Rio de Janeiro: Editora FGV.

Marinho, F. C., Souza, A. C. B. de, SILVA, J. L. G. da, Meirelles, E. G., \& Pinto Junior, D. M. (2013). Transporte de cargas: uma análise sobre os modais e sua aplicação na região Sul Fluminense. Revista ADMpg Gestão Estratégica, 6(1), 37-45.

Marques, C. F., \& Oda, E. (2012). Atividades técnicas na operação logística. Curitiba: IESDE Brasil S.A.

Melquiades, J. A. R. (2015). Modelagem para a roteirização do processo de coleta e transporte dos resíduos sólidos urbanos. Tese de doutorado, Universidade de Brasília, Brasília, DF, Brasil.

Mma - Ministério do Meio Ambiente. (2014). Inventário Nacional de Emissões Atmosféricas por Veículos Automotores Rodoviários. Recuperado em 10 junho, 2018, de

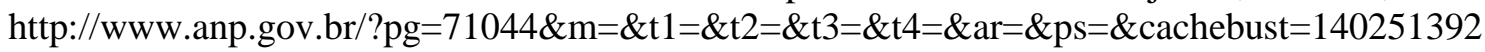
9715.

Morais, C. F. de, \& Colesanti, M. T. de M. (2014). Proposta de tratamento alternativo para resíduos sólidos urbanos na Cidade de Uberlândia - MG. Caminhos de Geografia, 15(52), 100-118.

Novo, A. L. A. (2016). Perspectivas para o consumo de combustível no transporte de carga no Brasil: uma comparação entre os efeitos estrutura e intensidade no uso final de energia do setor. Dissertação de mestrado, Universidade Federal do Rio de Janeiro, Rio de Janeiro, RJ, Brasil.

Nunes, R. R., \& Silva, R. A. P. da. (2015). Transbordo de resíduos sólidos. Revista Pensar Engenharia, 3(1), 1-18.

Nunnenkamp, C. H., \& Corte, A. P. D. (2017). Emissão de gases de efeito estufa e proposta de projeto para compensação: um estudo de caso e-commerce. Biofix Scientific Journal, 2(1), 69-77.

Padula, R. (2008). Transportes - fundamentos e propostas para o Brasil. Brasília: Confea.

Petrobras - Petróleo Brasileiro S. A. (2018). Preço de venda às distribuidoras. Recuperado em 25 maio, 2018, de http://www.petrobras.com.br/pt/produtos-e-servicos/composicao-de-precos-devenda-as-distribuidoras//.

Pidd, M. (1998). Modelagem empresarial: ferramentas para tomada de decisão. Porto Alegre: Artmed.

Pnlt - Plano Nacional de Logística e Transportes. (2009). Relatório Executivo PNLT. Recuperado em 15 setembro, 2017, de http://www.youblisher.com/p/248996-RELATORIO-PNLT-2009/.

Pontes, H. L. J., Carmo, B. B. T. do, \& Porto, A. J. V. (2009). Problemas logísticos na exportação brasileira da soja em grão. Revista Eletrônica Sistemas \& Gestão, 4(2), 155-181. 
Rodrigues, W., Magalhães Filho, L. N. L., \& Pereira, R. dos S. (2016). Análise dos determinantes dos custos de resíduos sólidos urbanos nas capitais estaduais brasileiras. Revista Brasileira de Gestão Urbana, 8(1), 130-141.

Santos, A. R. dos, \& Silva, H. A. da. (2015). Modais de transporte rodoviário e ferroviário: comparativo de viabilidade para escoamento da carga de uma multinacional produtora de cimento e agregados. Revista Sodebras, 10(115), 91-96.

Santos, S. dos. (2011). Transporte ferroviário: história e técnicas. São Paulo: Cengage Learning.

Santos, S. T. dos. (2012). Trecho ferroviário do gargalo do Paraguaçu: um impasse sobre a eficiência energética da ferrovia Centro - Atlântica. Trabalho de conclusão de curso, Universidade Estadual de Feira de Santana, Feira de Santana, BA, Brasil.

Seleme, R., Tejada, A. C., Paula, A. de, Castanheira, N. P., \& Cardoso, O. R. (2012, outubro). Avaliação dos modais de transporte rodoviário e ferroviário de commodities agrícolas (soja) da região oeste do Estado do Paraná ao porto de Paranaguá. Anais do Encontro Nacional de Engenharia de Produção, Bento Gonçalves, RS, Brasil, 32.

Silveira, M. R. (2003). A importância geoeconômica das estradas de ferro no Brasil. Tese de doutorado, Universidade Estadual Paulista, Presidente Prudente, SP, Brasil.

Simonetto, E. de O., Putnik, G., Rodrigues, G. O., Alves, C., \& Castro, H. de. (2016). Um modelo de dinâmica de sistemas para avaliação do reaproveitamento de resíduos eletrônicos na remanufatura de computadores em uma instituição de ensino superior. Exacta, 14(3), 385-402.

Simonetto, E. de O., Rodrigues, G. O., Dalmolin, L. C., \& Modro, N. R. (2014). O uso da dinâmica de sistemas para avaliação de cenários da reciclagem de resíduos sólidos urbanos. Revista Geintec, 4(2), 910-924.

Souza, D. F. de, \& Markoski, A. (2012). A competitividade logística do Brasil: um estudo com base na infraestrutura existente. Revista de Administração, 10(17), 135-144.

Souza, G. C. de, \& Guadagnin, M. R. (2009, agosto). Diagnóstico dos serviços de coleta, transporte, tratamento e disposição final de resíduos sólidos domiciliares em município de pequeno porte: estudo de caso em Cocal do Sul-SC. Anais do Seminário Regional Sul de Resíduos Sólidos, Caxias do Sul, RS, Brasil, 3.

Strauss, L. M. (2010). Um modelo em dinâmica de sistemas para o ensino superior. Dissertação de mestrado, Universidade Federal do Rio Grande do Sul, Porto Alegre, RS, Brasil.

Trombeta, L. R., \& Leal, A. C. (2014). Gestão dos resíduos sólidos urbanos: um olhar sobre a coleta seletiva no Município de Presidente Prudente, São Paulo, Brasil. Revista Formação, 21(1), 143 169.

Ventana Systems. (2016). Vensim Simulation Software. Recuperado em 10 junho, 2018, de http://www.vensim.com.

Vieira, J. de C. (2015). Desafios da ferrovia de integração do centro-oeste no cerrado. Revista Brasileira de Desenvolvimento Regional, 3(2), 55-72.

Wanke, P. F. (2010). Logística e transporte de cargas no Brasil: produtividade e eficiência no século XXI. São Paulo: Atlas.

Zioni, S., \& Freitas, S. R. de. (2015). Aspectos ambientais no Plano Nacional de Logística e Transporte do Brasil. Desenvolvimento e Meio Ambiente, 35, 195-208. 